1 Institut Pasteur, Emerging Diseases Epidemiology Unit, Paris, France

2 Norwegian Institute of Public Health, Oslo, Norway

3 Usher Institute of Population Health Sciences and Informatics, Edinburgh Medical School, University of Edinburgh, Edinburgh, UK

Correspondence to: A Fontanet arnaud.fontanet@pasteur.fr

Cite this as: BMJ2021;372:n524 http://dx.doi.org/10.1136/bmj.n524 Published: 24 February 2021

\title{
Covid-19: Keeping schools as safe as possible
}

\author{
A growing menu of effective measures can and should be deployed
}

\author{
Arnaud Fontanet, ${ }^{1}$ Rebecca Grant, ${ }^{1}$ Margrethe Greve-Isdahl, ${ }^{2}$ Devi Sridhar ${ }^{3}$
}

A year into the pandemic, and confronted with continued resurgence in transmission, over 800 million schoolchildren, more than half the world's student population, still face substantial disruptions to their education. These range from full school closures in 31 countries to reduced or part time academic schedules in another 48 countries. ${ }^{1}$ Some countries, such as Norway and France, chose largely to keep their schools open (only 7 and 10 weeks of school closure, respectively), whereas countries such as Germany and the UK have relied more often on school closure for epidemic control (19 and 21 weeks, respectively).

Although evidence has accumulated that school outbreaks are limited in number and size and that mitigation measures are effective, ${ }^{2}$ the emergence of variants with increased transmissibility ${ }^{3}$ raises uncertainty. It is therefore important to revisit how schools can be kept open without becoming centres of SARS-CoV-2 transmission.

Outbreaks in schools have been described throughout 2020-for example, in Israel ${ }^{4}$ and Chile ${ }^{5}$; however, these outbreaks tend to be limited, ${ }^{6}$ partly because children are $30-50 \%$ less susceptible to infection than adults $^{7}$ and have no or mild symptoms when infected. ${ }^{29}$ Transmission has been described between pupils, between teachers and pupils, and among teaching and non-teaching staff. ${ }^{10}$

As children have mild forms of disease and teachers are able to protect themselves effectively-their rate of infection is similar to that of adults of the same age and sex $^{2}$-the biggest risk associated with schools lies in transmission of the virus from children to parents and grandparents vulnerable to developing severe forms of covid-19. Infected children, particularly those younger than 10 years, are probably less contagious than infected adults. ${ }^{78}$ Nonetheless, schools may contribute to community transmission, and some, ${ }^{11}$ but not all, ${ }^{12}$ models consider school closures an important component of epidemic control. The emerging consensus is that schools do not seem to be amplifiers of transmission, and that cases in schools simply reflect prevalence within the local community. $^{2}$

\section{Minimising harm}

A decision to maintain in-person learning goes beyond strict epidemic control, however. Children and adolescents are suffering from the effect of repeated lockdowns and disruptions to schooling, ${ }^{1314}$ as shown by the latest updates of the Mental Health of Children and Young People Survey and the YoungMinds survey in the UK, ${ }^{15}{ }^{16}$ and by increases in anxiety disorders and suicide attempts. ${ }^{1718}$ Closing schools risks detrimental effects on children's educational attainment and their social and mental development. For many children, schools are also a source of food or security from domestic violence. The economic implications of closing schools must also be considered, including loss of parental income linked to childcare or supervision of online learning, particularly for younger children. These economic effects fall disproportionately on women. School closures augment existing social inequities, compounded by the fact that areas of social deprivation, often associated with multigenerational housing and public facing occupations, tend to be areas of greater transmission. ${ }^{19}$

The decision to reopen schools or keep them open despite community transmission must be accompanied by effective risk mitigation measures. ${ }^{20}$ Most importantly, children and staff with symptoms must be kept out of school, although this alone cannot stop transmission by those who are asymptomatic or presymptomatic. ${ }^{2}$ This needs to be accompanied by contact tracing and quarantine of close contacts. Compliance with quarantine can be particularly challenging for children with parents who cannot work from home, so supporting parents or guardians to care for isolating or sick children may prove beneficial.

Most European countries have introduced measures ${ }^{220}$ to reduce transmission such as cohorting of pupils, physical distancing, improving ventilation of indoor settings, moving physical activities outdoors, regular cleaning of surfaces, and improving hand hygiene and respiratory etiquette. These measures also need to apply beyond the classroom, particularly transport to and from school, during pick-up and drop-off times for both children and adults, and during meal times in the school day. The use of face coverings, particularly for primary school children, ${ }^{20}{ }^{21}$ and blended learning (a mixture of online and in-person learning) in secondary schools have been more contested, but may help to keep schools open in the presence of more transmissible variants. Use of saliva testing or lateral flow testing for surveillance in schools and prioritisation of teachers for immunisation should also be considered.

The most important thing we can do to keep schools safe is to reduce transmission in the community, ${ }^{20}$ particularly in areas of social deprivation. Reopening of schools should be phased, at a time when community transmission of the virus is controlled, and with primary school aged children prioritised for returning to the classroom to minimise both transmission within schools and the disruption caused by school closures. Although the roll-out of effective vaccines has begun, controlling transmission is even more important to keeping 
children in the classroom as viral variants with increased transmissibility gain hold in many countries around the world.

Competing interests: We have read and understood BMJ policy on declaration of interests and declare the following interests: AF is a member of the French Covid-19 Scientific Council. DS is a member of the Scottish and the UK Cabinet Office covid-19 advisory groups.

1 United Nations Educational, Scientific and Cultural Organization. UNESCO figures show two thirds of an academic year lost on average worldwide due to Covid-19 school closures. 2021. https://en.unesco.org/news/unesco-figures-show-two-thirds-academic-year-lost-averageworldwide-due-covid-19-school.

2 European Centre for Disease Prevention and Control. COVID-19 in children and the role of school settings in transmission-first update. 2020. https://www.ecdc.europa.eu/en/publications-data/children-and-school-settings-covid-19-transmission.

3 Volz E, Mishra S, Chand M, etal. Transmission of SARS-CoV-2 lineage B.1.1.7 in England: Insights from linking epidemiological and genetic data.MedRxiv 2021. [Preprint.] doi: 10.1101/2020.12.30.20249034.

4 Stein-Zamir C, Abramson N, Shoob H, etal. A large COVID-19 outbreak in a high school 10 days after schools' reopening, Israel, May 2020. Euro Surveill 2020;25:2001352. doi: 10.2807/1560-7917.ES.2020.25.29.2001352 pmid: 32720636

5 Torres JP, Piñera C, De La Maza V, etal. SARS-CoV-2 antibody prevalence in blood in a large school community subject to a Covid-19 outbreak: a cross-sectional study. Clin Infect Dis 2020:ciaa955. doi: 10.1093/cid/ciaa955 pmid: 32649743

6 Otte Im Kampe E, Lehfeld AS, Buda S, Buchholz U, Haas W. Surveillance of COVID-19 school outbreaks, Germany, March to August 2020. Euro Surveill 2020;25:2001645. doi: 10.2807/1560-7917.ES.2020.25.38.2001645 pmid: 32975186

7 Thompson HA, Mousa A, Dighe A, etal. SARS-CoV-2 setting-specific transmission rates: a systematic review and meta-analysis. Clin Infect Dis 2021:ciab100. doi: 10.1093/cid/ciab100 pmid: 33560412

8 Viner RM, Mytton OT, Bonell C, etal. Susceptibility to SARS-CoV-2 infection among children and adolescents compared with adults: a systematic review and meta-analysis. JAMA Pediatr 2021;175:143-56. doi: 10.1001/jamapediatrics.2020.4573 pmid: 32975552

9 Dong Y, Mo X, Hu Y, etal. Epidemiology of covid-19 among children in China. Pediatrics 2020;145:e20200702. doi: 10.1542/peds.2020-0702 pmid: 32179660

10 Ismail SA, Saliba V, Lopez Bernal J, Ramsay ME, Ladhani SN. SARS-CoV-2 infection and transmission in educational settings: a prospective, cross-sectional analysis of infection clusters and outbreaks in England. Lancet Infect Dis 2020:S1473-3099(20)30882-3. pmid: 33306981

11 Li Y, Campbell H, Kulkarni D, etal. The temporal association of introducing and lifting non-pharmaceutical interventions with the time-varying reproduction number (R) of SARS-CoV-2: a modelling study across 131 countries. Lancet Infect Dis 2021;21:193-202. doi: 10.1016/S1473-3099(20)30785-4

12 Flaxman S, Mishra S, Gandy A, etallmperial College COVID-19 Response Team. Estimating the effects of non-pharmaceutical interventions on COVID-19 in Europe. Nature 2020;584:257-61. doi: 10.1038/s41586-020-2405-7 pmid: 32512579

13 Lee J. Mental health effects of school closures during COVID-19. Lancet Child Adolesc Health 2020;4:421. doi: 10.1016/S2352-4642(20)30109-7 pmid: 32302537

14 Newlove-Delgado T, McManus S, Sadler K, etalMental Health of Children and Young People group. Child mental health in England before and during the COVID-19 lockdown. Lancet Psychiatry 2021:S2215-0366(20)30570-8. doi: 10.1016/S2215-0366(20)30570-8. pmid: 33444548

15 Vizard T, Sadler K, Ford T, et al. Mental health of children and young people in England 2020, Wave 1 follow-up to the 2017 survey. 2020. https://files.digital.nhs.uk/CB/C41981/mhcyp_2020_rep.pdf.

16 YoungMinds. Coronavirus: impact on young people with mental health needs. 2020. https://youngminds.org.uk/about-us/reports/coronavirus-impact-on-young-people-with-mentalhealth-needs/.

17 Leeb RT, Bitsko RH, Radhakrishnan L, Martinez P, Njai R, Holland KM. Mental health-related emergency department visits among children aged <18 years during the covid-19 pandemic United States, January 1-October 17, 2020. MMWR Morb Mortal Wkly Rep 2020;69:1675-80. doi: 10.15585/mmwr.mm6945a3 pmid: 33180751

18 Hill RM, Rufino K, Kurian S, Saxena J, Saxena K, Williams L. Suicide ideation and attempts in a pediatric emergency department before and during COVID-19. Pediatrics 2020:e2020029280 . doi: 10.1542/peds.2020-029280 pmid: 33328339

19 Bambra C, Riordan R, Ford J, Matthews F. The COVID-19 pandemic and health inequalities. J Epidemiol Community Health 2020;74:964-8.pmid: 32535550

20 World Health Organization, Unicef, Unesco. Considerations for school-related public health measures in the context of COVID-19: annex to considerations in adjusting public health and social measures in the context of COVID-19.2020. https://apps.who.int/iris/handle/10665/334294.

21 Hobbs CV, Martin LM, Kim SS, etalCDC COVID-19 Response Team. Factors associated with positive SARS-CoV-2 test results in outpatient health facilities and emergency departments among children and adolescents aged < 18 years - Mississippi, September - November 2020. MMWR Morb Mortal Wkly Rep 2020;69:1925-9.

doi: 10.15585/mmwr.mm6950e3 pmid: 33332298
This article is made freely available for use in accordance with BMJ's website terms and conditions for the duration of the covid-19 pandemic or until otherwise determined by BMJ. You may use, download and print the article for any lawful, non-commercial purpose (including text and data mining) provided that all copyright notices and trade marks are retained. 